\title{
Gender Discrimination and Well-Being: The Case of Physics inside the Science, Technology, Engineering, and Mathematics Sector in Italy
}

\author{
Federica D’Isanto', Grazia Barone², Maria Rosaria Masullo³ \\ ${ }^{1}$ Department of Political Sciences, Universita degli Studi di Napoli Federico II, Napoli, Italy \\ ${ }^{2}$ Independent Researcher and Therapist, Napoli, Italy \\ ${ }^{3}$ Istituto Nazionale di Fisica Nucleare, Sezione di Napoli, Napoli, Italy \\ Email: federica.disanto@unina.it, grazia.barone@hotmail.it, masullo@na.infn.it
}

How to cite this paper: D'Isanto, F., Barone, G., \& Masullo, M. R. (2021). Gender Discrimination and Well-Being: The Case of Physics inside the Science, Technology, Engineering, and Mathematics Sector in Italy. Open Journal of Philosophy, 11, 444-465. https://doi.org/10.4236/ojpp.2021.114030

Received: August 4, 2021

Accepted: October 16, 2021

Published: October 19, 2021

Copyright (c) 2021 by author(s) and Scientific Research Publishing Inc. This work is licensed under the Creative Commons Attribution International License (CC BY 4.0).

http://creativecommons.org/licenses/by/4.0/

\begin{abstract}
This paper analyses the phenomenon of gender discrimination in the science, technology, engineering, and mathematics (STEM) sector, which has always been known for its strong segregation, both horizontal and vertical. Our purpose is to uncover more hidden mechanisms of gender discrimination, such as those that refer to the implemented organizational models. The sample used is the universe of the INFN (National Institute for Nuclear Physics) division in Naples (Italy). For our study, we used semi-structured interviews and an interpretation model as one of the structural inferences. The results show that the organizational models adopted by INFN penalize women, but often men too, which can be traced to the way society and the labor market are structured. In general, the interviewees showed enthusiasm to work in the research field, even if in this context the adopted work organization model was limited and restricted, unable to value diversity and transversal skills. A different perception of time management between women and men leads in the former to a feeling of dichotomy as a source of malaise. Consequently, it can be said that there is a form of inequality (or discrimination) related to women's well-being and that they have a worse quality of life.
\end{abstract}

\section{Keywords}

Gender Discrimination, Gender Diversity, Working Conditions, Work Organization, Quality of Life, Work Psychology

\section{Introduction}

Nowadays, although work organizations have understood the importance of in- 
creasing female participation and emphasize the value of integrating sex and gender analysis into labor processes, this does not mean that they have understood and considered all the gender discrimination mechanisms. Gender discrimination in the labor market is a well-studied topic (Becker, 1957; Blinder, 1973; Greig et al., 2018; Comoletti \& D’Isanto, 2019) which has evolved over time, presenting itself in completely new forms and nuances that often make it difficult to identify.

Discriminatory mechanisms can be summarized in two main categories: ones that exist prior to entering the labor market (pre-labor market or ex-ante mechanisms) and those that have their origin in the labor market (labor market discrimination or ex-post) (Oaxaca \& Ransom, 1994). The former case refers to characteristics acquired before accessing the labor market and which can cause discrimination, such as "family background" or "social background" (Becker, 1975). In the latter case, discrimination in the labor market can take the form of direct wage discrimination (Becker, 1957) or it can refer to allocation into specific sectors (horizontal segregation) or duties (vertical segregation) (Anker, 1997; Becker, 1985; Bergman, 1974; Bettio, 2008; D’Isanto, 2013).

According to these classifications, three main phases of gender inequality can be identified: inequality in securing job opportunities; inequality in wages; and inequality in career progression. Analyzing the work organization environment, these phases appear to be influenced by organizational model, time management structure and productivity indicators.

Gender discrimination and iniquities also mainly depend on work organization (Acker, 1990, 1992; Aaltio \& Mills, 2003). Gendering processes are often implicit in behaviors and practices, which appear neutral but result in measurable differences in treatment and experiences between women and men. As defined by (Acker, 1990), these gender differences and hierarchies are produced across four gendered dimensions, all of which are based on masculine values and ideal models: the division of labor; relations in the workplace; the construction of symbols; and the interpretations of one's individuality within the organization. These gendered processes can be hidden within norms, practices and values which are taken for granted, and inevitably represent a disadvantage and discrimination towards those with different values and life experiences. They affect not so much the conventional discrimination indicators, such as horizontal and vertical segregation, contract typology, and career progression, but other indicators relevant to the quality of life of individuals. In these maledominated environments, women will try to adapt their identity to the perceived gender expectation, such as trying to be one of the men (Powell et al., 2009). Although women may earn the same wage, have the same contract, or hold positions as leaders, their quality of life is much worse than that of their male colleagues.

Many authors have investigated the complexities of the relationship between women and well-being in the workplace, considering different factors ranging from greater family demands, to lower wages, and to the socio-political context 
(Lennon, 1994; Ravenswood et al., 2017; Connerley \& Wu, 2019). Some authors found that some indicators of gender equality are negatively connected to women well-being (Meisenberg \& Woodley, 2015). The relationship between women and well-being is a subject that still requires investigation, as (Batz \& Tay, 2018) underlined in their work.

The purpose of the following analysis is to capture more hidden dimensions of gender discrimination in a labour organization through the analysis of working conditions, considering not only the conventional indicators but also elements that affect women's quality of life.

Developing a research method to evaluate gender discrimination inside labor organizations in terms of human well-being could be the right way to give value to gender diversity and to improve workers' conditions. We introduce the gender well-being gap as an indicator, a dimension of gender discrimination. The study was conducted on women and men working at a public Italian Physics research institute.

Over the last 20 years, continuous steps and changes have been made to advance gender equality in research institutions around the world (COM 392 Final Report, 2012; Maes et al., 2012; Huyer, 2015; Global Research Council, 2016). However, gender discrimination is still present in the sector (She Figures 2018 Report, 2018; Nielsen et al., 2018) and the related phenomena are not all clearly recognizable. Physics inside the STEM disciplines is characterized by its strong gender segregation, both horizontal and vertical, as shown by the underrepresentation of women in different fields of research and/or in top positions (Rolin \& Vainio, 2011; She Figures 2018 Report, 2018).

In order to understand gendering processes, our data collection was based on semi-structured interviews, with the aim of identifying indirectly the existence of gender discrimination mechanisms (Williams et al., 2012) by gathering information about the work conditions of all the employees. The interpretation model adopted was one taken from the clinical setting and applied to work psychology (Di Nuovo \& Rispoli, 2011). We analyzed the work organization and some of its operating processes and practices, as represented by the thoughts of individuals and their perception of the work environment.

Gendered phenomena, as in the case of many other complex phenomena, cannot be explained simply by adding different factors, but it is necessary to incorporate and intersect different levels of analysis (Wood \& Ridgeway, 2010). Coming from the different fields of psychology, economics and physics, we started this research with three different approaches to the study of "women within the work organization". The analysis procedure can be generalized to other working contexts, underlying the need for an interdisciplinary approach.

In the following section, we will describe the sample studied and the methodology used. The results will be reported for the three different employee areas analyzed: Research, Administrative and Technical. Discussion of the results and policy implications will conclude the paper. 


\section{The Context of INFN}

Among all the Italian research institutes, we decided to analyze the National Institute for Nuclear Physics (INFN), which is dedicated solely to research in physics, in particular, to study the fundamental constituents of matter and the laws that govern them. It operates in close collaboration with the academic world as part of a wider international cooperation framework, and its work is internationally recognized, not only for its contribution to various European laboratories but also to numerous research centres worldwide. Moreover, the institute promotes and transfers the acquired knowledge, competences, methods and techniques developed as part of its own research activities to other disciplines such as medicine, art heritage and the environment. Its research activities are conducted with two types of structure: Divisions and national laboratories. The four national laboratories, based in Catania, Frascati (Rome), Legnaro (Padova) and Gran Sasso (L'Aquila), house large equipment and infrastructures available for use by the national and international scientific community. Each of the 20 divisions is based inside different university physics departments and guarantees close collaboration between the INFN and the academic world (see Figure 1).

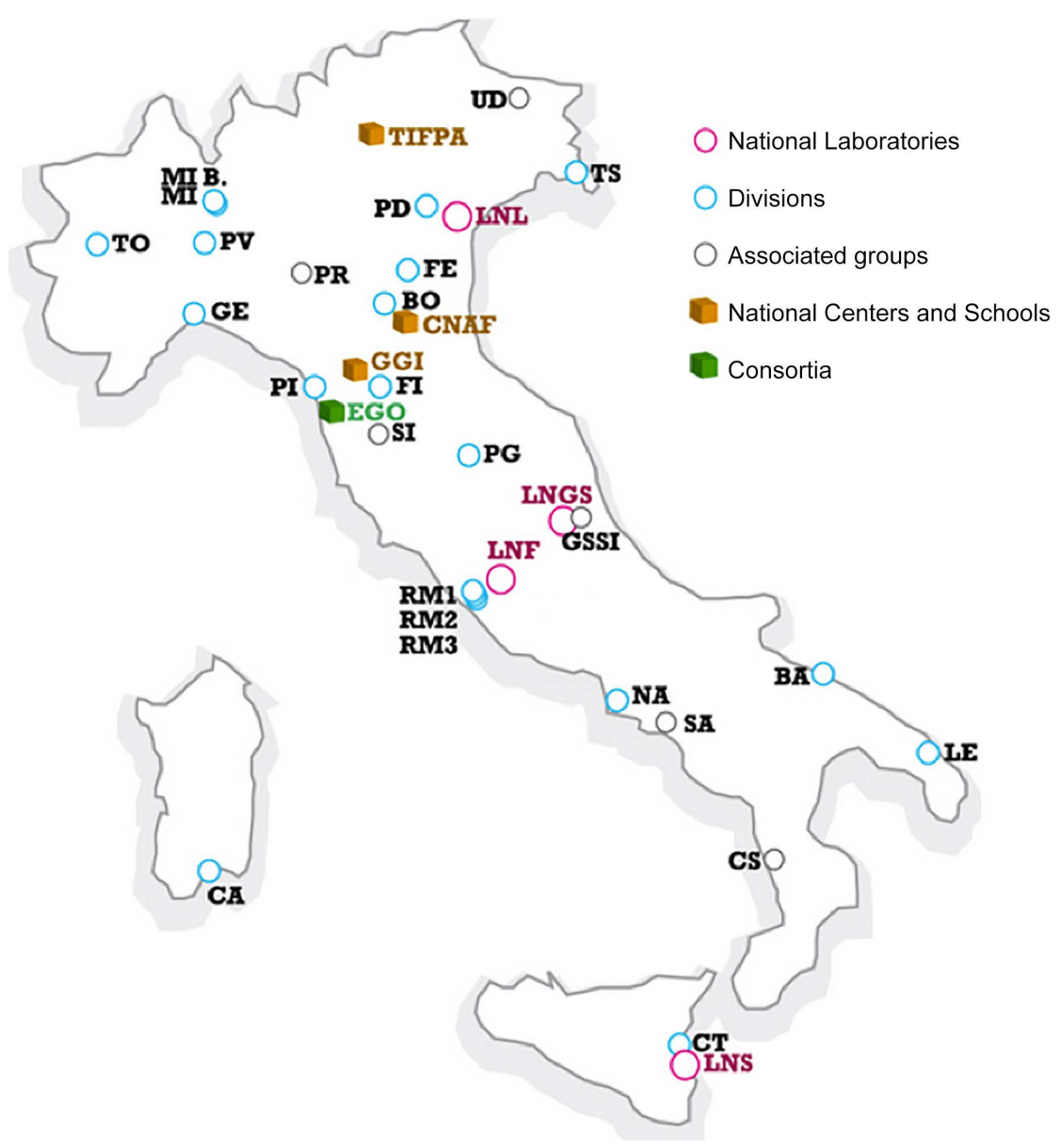

Figure 1. Distribution of INFN facilities (INFN, 2018) (Source: INFN http://home.infn.it/en/structure/map-of-infn-facilities). 
The governing council is the decision-making body of the institute, composed of the INFN president, executive board and directors of all the laboratories and divisions. Management is to an extent centralised, even if each division has relative independence with its own director.

Regarding gender policies, INFN has its own Affirmative Action Plan ratified by the governing body and an internal Guarantee Committee for Equal Opportunities, Employee Wellbeing and Non-Discrimination, which works for equal opportunities and well-being at work. However, gender issues are still not embedded in the human resource program and are separate from the research programs.

At present, following the 2019 performance report ${ }^{1}$, the INFN employs 2000 people, plus roughly 3000 associate scientists from universities and other research institutions. The female employee distribution is roughly $22 \%$ of researchers, $19 \%$ of technologists, $6 \%$ of technical staff and $80 \%$ of administrative staff. Among the researchers, only 1.4 out of each 10 women is at the top level, whereas this figure is double for men. From the beginning of our research (2015), the data have not changed for researchers, whereas the percentage of women technologists was lower (13\%) and higher for administrative staff (85\%), 1 out of 10 women were top researchers.

\section{The Sample}

Inside the framework of INFN, the sample we used is the universe ${ }^{2}$ of the Naples division, an important institution in the south of Italy, a region in a country where families may play a central role in women's experiences and choices, not only as a source of restraint, obligations and duties but also as a source of resources and support. The Naples division is mid-sized, located inside the biggest southern University, University "Federico II" of Naples. The employee composition of 2015 is shown in Table 1.

For our analysis, the population was divided into three areas: researchers and technologists, administrative staff, and technicians. Table 2 shows a breakdown of the sample studied.

\section{Methodology: The Semi-Structured Interviews. Narration as an Instrument to Reveal Oneself}

As previously mentioned, gendered processes can be hidden within the norms, practices and values taken for granted. Therefore, how can the fallout on people's quality of life be assessed? The impact upon people's well-being and work organization is stronger in environments where work and private life merge and blend together.

Our idea was to explore these mechanisms and processes from the point of view of the employees who spend their working life in the Naples division of INFN. This interest came from an INFN national research project on the evaluation ${ }^{1}$ https://performance.gov.it/performance/relazioni-performance/documento/1170.

${ }^{2}$ In this paper, with the word universe we analyze the entire realty of INFN in Naples as a whole. 
Table 1. Naples division employee composition by sex and working typology.

\begin{tabular}{ccc}
\hline Working typology & Women & Men \\
\hline Administrative staff & 7 & 3 \\
Researchers & 6 & 24 \\
Technical staff & 0 & 16 \\
Technologists & 1 & 8 \\
Fellows & 5 & 8 \\
Scholarships & 1 & 5 \\
Total & 20 & 64 \\
\hline
\end{tabular}

Table 2. Sample composition by sex and working typology.

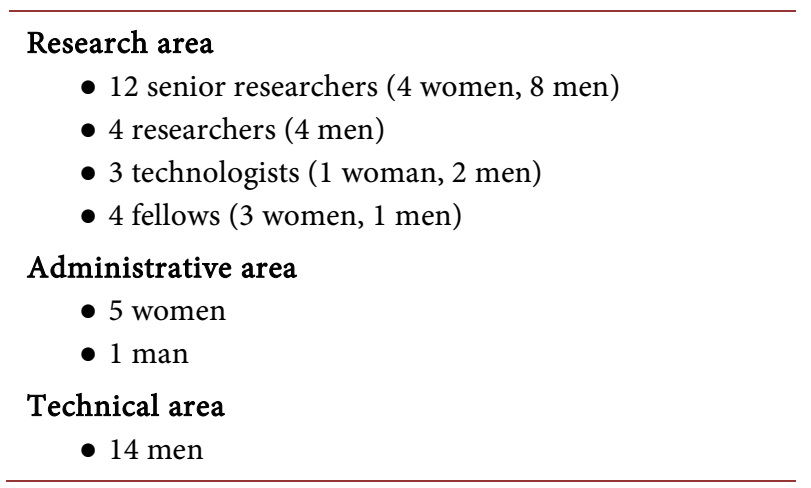

of organizational well-being ${ }^{3}$, in relation to the ability of an organization to be effective and productive, as well as capable of developing and fostering psychophysical wellness. The investigation, conducted in the form of a questionnaire, showed the need to reflect on certain critical points through a better knowledge of oneself and one's work environment.

In this context, the health condition of workers is defined not only as the absence of disease, but must include their state of psychophysical well-being, which is a part of the multidimensional framework of organizational well-being strictly connected to the health of the organization (Di Nuovo \& Rispoli, 2011).

To investigate the connection between working conditions, gender organization and well-being, we choose to employ semi-structured interviews in order to hold together the theoretical framework, the structure and the interviewees' freedom of expression and narration. Inside qualitative data collection strategy, semi-structured interviews are characterized by a set of predetermined but open-ended questions and topics to be covered during the interview. The sequence of questions can vary and also new questions can arise from the conversation. This was for us the starting point for analysing how gender is embedded in the organizational work logic (Acker, 1990; Bruni et al., 2004; Poggio, 2006).

In accordance with Anglo-American woman scholars, who have been devel${ }^{3}$ INFN evaluated its organizational well-being within the Magellano project, sponsored by the Department of Public Administration (National Project for the Evaluation of Organizational Well-being). 
oping a feminist methodology since the early seventies (Harding, 1987; Gherardi \& Poggio, 2007), interviews prove to be one of the most fruitful instruments to achieve research that aims to be attentive to gender issues. In a constantly evolving text, such an instrument can overturn the relationship between the object and the interviewer, allowing the latter to share a common field where skills, experiences and emotions are involved.

During our interviews, we analyzed three areas: the working history, the working-life balance and the organizational culture. For each area, we devised model questions believed to establish a relationship with the employees of the institute. We recorded the 49 interviews (40 - 50 minutes long), conducted in person, and then transcribed them in full. The interviews took place in offices or laboratories inside the INFN structure. The first step of this ideographic research involved a privileged qualitative approach to create a "place" where individuals could think of themselves as the subjects, and then as subjects related to a work context whose dynamics could be read from a gender perspective.

We processed the data from the interviews employing functional analysis (Rispoli, 2008), not in search of "pathology" or "therapeutic settings", but as a process for understanding the basic functioning of the organism-organization of the INFN division. The Neo-functionalism outlines the deepest, multidimensional functioning of an organism (the self), observing the way systems are organized internally (mind-body functions), together with their functioning. From this perspective, work organizations must be considered as organisms with a brain, heart and breath, and a measure of their health is the capability to promote the individual and collective well-being of employees.

If the result of setting free paralyzed energies, together with the promotion of resources to achieve greater satisfaction, is to have better work capacities, we need to acquire self-awareness as individuals and as a group to achieve the idea of bien-être (which is more than well-being in terms of productivity or reaching goals). This means that we have to examine the deepest functioning and expression of the organism (the roots of thoughts, behaviours and emotions). The functional interpretation divides the organism's functions into four main areas: cognitive-symbolic, emotive, morphological and physiological, as shown in Figure 2.

In order to give a complete profile of the INFN Naples division, we used this approach to analyze how the employees deal with life and work experiences and consequently how their functions can be altered. This will enable us to identify any damaged and/or intact functions of the institute.

It should be underlined that neo-functionalism has widely used functional analysis, taken from clinical psychology, to assess stress within companies (Di Nuovo \& Rispoli, 2011). This methodology is used to examine individuals' abilities and qualifications compared to the specific demands and expectations within private and public organizations. In this case, we have chosen interviews instead of questionnaires because we wanted the narrations to speak for themselves 


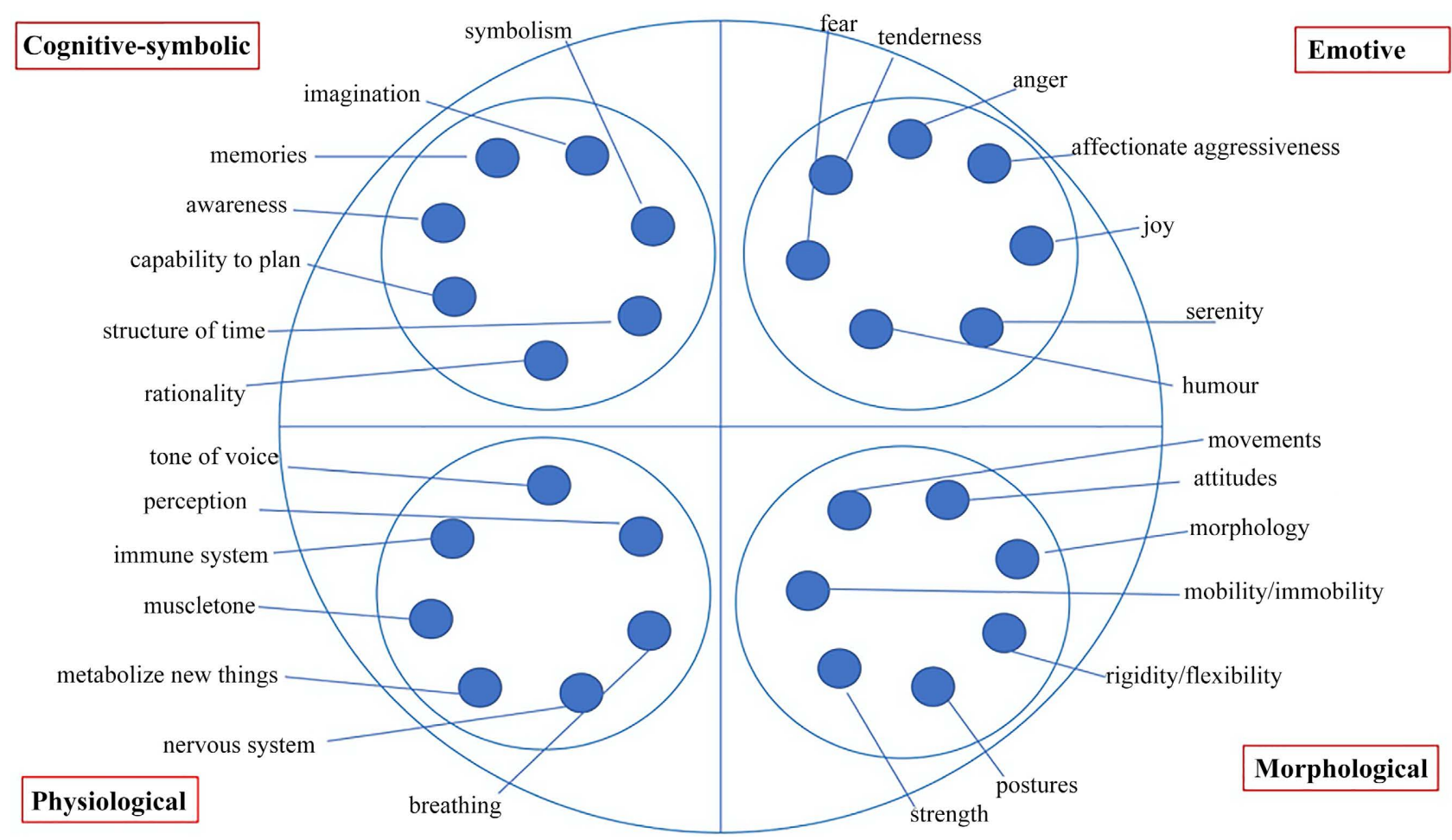

Figure 2. Functions of the Organization (based on: (Di Nuovo \& Rispoli, 2011)).

as a process of acknowledgment and of social acting; that is, as an interpretation of what the workers experience in their life (Denzin, 1989).

We used functional analysis to give a voice to each group (researchers, technologists, technicians and administrative staff) through the voice of individuals (Lewin, 1947).

\section{Functional Analysis ${ }^{4}$}

As previously mentioned, the sample was divided into three areas: Research (researchers and technologists), Administrative (administrative staff), and Technical (technicians). Because each area is a group with a different history, needs and problems, we performed a separate functional analysis for area. Only inside the Research area, we realized two different analyses: one for women and one for men, because the two subgroups are larger with respect to other areas.

Four functional levels have been studied (Rispoli, 2008):

- Cognitive-symbolic, which regards functions such as imagination, memories of the past, awareness, capability to plan, and rationality;

- Emotive, which refers to functions such as fear, anger, affectioned aggressiveness, and joy;

- Morphological (muscular/postural), where functions relate to the "space" in which individuals work and how they move within it, such as postures, attitudes, rigidity and flexibility;

${ }^{4}$ Hereafter, italics will be used for phrases and words extracted from the interviews, while sentence or words in quotation marks indicate key concepts. 
- Physiological, which regards functions such as the tone of voice, breathing and perception.

Some functions and employee areas appear more distinctive than others; for this reason, in some cases, we discussed these in more detail than others. From all the interviews, we extracted relevant elements, which are reported in italics in the text. These came mostly from the Research area. For this reason, we mainly report content that refers to this area.

\subsection{Research Area}

The researcher and technologist area include mainly men, permanent staff and fellows. Many of the researchers and technologists were involved in academic activities in terms of teaching duties, such as thesis supervision and delivering lessons. Being involved in international and national collaborations, short- and long-term mobility is necessary, which greatly affects the private-working life balance. The wage difference within this area is mainly due to career progression and to the greater difficulties encountered by women.

From this point, the term "researchers" is used to refer to "researchers and technologists", as they are analysed as one category.

In the case of Cognitive-symbolic and Emotive levels, the functional analysis is reported separately for women and men. The analysis of the other two levels (Morphological and Physiological) is based on observation of their work environment and not from participants' answers to our questions. For this reason, we combined female and male researchers in the following discussion.

\section{Cognitive-Symbolic level}

Female researchers. The sense of belonging amongst female researchers is very strong: they make their contribution to the institute not only through their work, but also on more personal level (they often gather together when the library closes and have a yoga lesson with a trainer who is a female researcher herself). They all think that on one hand, INFN is very innovative, dynamic and modern on a scientific level, but on the other that it is "old", because it is not able to offer a permanent position to all the young researchers, already well trained inside the institute. The general feeling that emerged was that the work organization was lacking in terms of job opportunities and career progression.

It was very difficult to make a career... $\mathrm{P}$ m a qualified professor but perhaps I will never be a research director. [...] $P_{m}$ afraid that the institution is becoming too bureaucratic and is losing the characteristics it was born with, when there was simple management partly based on relationships among people... the lack of young people... [...] (Senior female researcher).

Knowledge transmission and communication between young female and senior researchers are very good; senior ones are recognized as tutors able to listen to and guide those with less experience. Generally, their relations are positive.

Well, yes, my research group has always...always supported me. I found the environment very positive (Young female researcher). 
However, the uncertainty of temporary work affects their future and life planning, and any possibility of influencing the work organization.

At present perhaps... if the money comes in, Ill have some more years as a fellow. But I don't know about the future... I can't rely on grant money for ever, so you think about something else... (Young female researcher).

The female fellows know that what they are doing is gratifying and fascinating, but that it is temporary and fixed-time work.

In addition, for the seniors, things become uncertain and confused when they speak about career possibilities:

[...] in the present situation, a professional evolution is difficult. I $m$ not so ambitious. I love my work... I $m$ happy anyway. But it's true that there are no incentives for taking on new responsibilities because some of them are not useful for careers [...]. This institution has changed a lot...in the past you had more money and more freedom to go on missions (Senior female researcher).

Female group coordinators suffer in terms of their role recognition inside the institute:

Im the only woman in this branch...I coordinate a group of all men... Men don't accept a woman with superior responsibilities. I had to defend myself, even becoming aggressive... (Senior female researcher).

Male researchers. For this group, the project and cognitive-symbolic functions are merged with the history of the individual, as they see the institution as the place where they can realize their own idea about research, experiment and work relations.

At beginning of their careers, many senior researchers were given great opportunities by the institute just after their graduation; they were satisfied and gratified with their initial careers and they felt "lucky". However, later, after accepting, training and guiding them, the institution became something with which the male researchers could no longer identify. They continued their work, producing high quality research, even if their career progression was not guaranteed. Individuals had their dreams, but not at the institute:

[...] The only thing you can hope is that the commitment and the sacrifices, for example in taking major responsibility in an international cooperation, will be recognized when promotions are made... Unfortunately, today open recruitment has become less frequent, with only a few positions, so it seems there is no correspondence between the efforts made and promotions... [...] (Senior male researcher).

General awareness of negative aspects arises from their interviews, but their curiosity and passion for their jobs keep the staff going.

The passion for research is what keeps me going, nevertheless, the world of research is not just fascination. It is made also of self-interest, mediocrity covered with apparent positivity; [...] ...I have done things, I have managed funds and so on ... and I started to think that if you go into this kind of mechanism you lose sight of what, for me, is the fundamental objective: knowledge (Senior male researcher). 
[...] there are obligations in the rules of public administration that don't let you make a career. That's it. Besides, if you want to complain about the institute we should say that in the past seniority was privileged; a system which was more democratic than a merit-based one assured progression for everybody... unfortunately the present rules don't allow either of the two. [...] $P \mathrm{~m}$ very pleased with the quality of my work. I have received recognition from outside the institute, which itself hasn't got the proper instruments to value individuals' work (Senior male researchers).

Regarding the transmission of knowledge, as in the case of the women, the male group underlined the fact that the institute is becoming old, because it was not able to benefit from young researchers' potentialities as staff.

Emotive level

Female researchers. If the serenity of doing a good job is threatened, enthusiasm for the work will often turn into agitation, with many women thinking that their workload and bureaucracy affect the quality and fluency of their work. They preserve a sense of pride linked to their feeling of belonging to the institute where they were trained and now work:

I grew up in the institute [...] (Senior female researcher).

From the analysis of this level, the problem of the balance between work and family is particularly evident. Many of the female researchers stated that the birth of a child made them reconsider their life priorities:

[...] after my child s birth, my life changed a little bit. During the first years, I still travelled, but later I had to choose a role that kept me here... without taking over any responsibilities (Senior female researcher);

[...] If my daughter is ill, I stay at home...my commitment is somehow rescheduled according to the needs of the girl... [...] (Senior female researcher);

When my first child was born I realized that my time was precious...I started to make better use of it and I did a lot... [...] (Senior female researcher).

In this context, it is interesting to underline the lack of awareness of evident gender discriminatory mechanisms.

[...] Im not saying that I was discriminated against as a woman because it would be too much, as it wasn't like that, anyway, I m sure that some people take into account your availability according to your sex or to your wish to have a family and...let's say that when they have to choose a person for their group they think that a man will be more available, and that may be true, he will be ready to travel... [...] because a woman will probably wish to have a family at a certain point. It wasn't important, but I felt it... [...] In such an environment I had to fight tooth and nail when I came back after maternity leave... [...] I took my roles back with a great effort (Senior female researcher).

In the life of these women, the work-family balance has been successful thanks to family support (relatives) or external help (babysitters or nurseries), although these choices are imbued with doubts, adjustments and conflicts. These women love both their children and their work; they want to take care of both, because 
both enrich their lives. A strong sense of gratitude to those who allowed them to focus on their work in peace emerged from the words of senior researchers.

The comfort of leaving them to their granny is invaluable and it helped me in many choices, [...] later I wondered if I made the right choice for my family [...] I think that you devote time to them, then they grow up and it's right that they go their way...So at some point, I decided to not feel influenced anymore, and I started travelling again, I take them with me whenever I can...I don't want them to see my work as something that takes their mummy away, but as something that enriches them (Senior female researcher);

My son was taken care of by a babysitter since the beginning... a reliable person. He went to a nursery school pretty soon... $\mathrm{P}$ grateful to the person who helped me take care of him and who still supports me because when I divorced. The most important thing for me was to take care of my son (Senior female researcher);

We had a lady who worked all day and was like a nanny to my girls [...]; anyway, I tried to be at home if one daughter wasn't feeling well... I couldn't come to work, when that happened. I used to sit on the floor, reading my article, and have my daughter on the sofa...I d say that I tried to delegate some things, but not all... also because I loved...I love to take care of them" (Senior female researcher).

Temporary female researchers feel and think that future maternity is an experience that slows or halts their career:

To have a baby means to have a break...and think that another person can take my place...this idea makes me anxious...on the other hand $1 \mathrm{~m}$ serene because at a certain point you make a decision and that's it... $\mathrm{m}$ not the one who thinks about a career... I just think that the PhD is important and I want to finish it (Young female researcher).

Affectionate aggressiveness, which is a function used to remove obstacles without becoming angry, is left aside because women need to adapt to masculine models in order to be accepted and recognized.

[...] By the time you realize that you have to raise your voice, or if you don't want to, you have to do more... If you are in a meeting or in a commission, where they appointed women by law (gender quota), you are often the only woman... and it's difficult because their criteria are always the same... their way of thinking, or talking... and so you have to find new strategies (Senior female researcher);

[...] Here, $P m$ the only woman in my research sector... $P m$ the coordinator of a group of all men... and men, you know, usually don't accept a woman with superior responsibilities. I had to defend myself, sometimes getting aggressive (Senior female researcher);

Moreover, different skills and requirements directly related to an experiment or work organization can penalize women:

[...] In some contests a physical presence is important...it depends on the job you are doing...if you working on the detector, and this is usually done in big 
laboratories, you have to stay there during the detector installation and construction and after to detect data... you cannot manage your time and you must be ready to stay away from home and your office for long periods (Senior female researcher).

In addition, in this case, the absence of gender awareness can be noted:

[...] I felt I had to demonstrate that I did more to be accepted, or at other times what I was doing was never enough, I don't know why. If you went home at five... it was noticed; if one of the young men went, no one noticed it... anyway I can't say I have been discriminated against... but I had to demonstrate more than the boys (Young female researcher).

Male researchers. Curiosity and interest in their work and new ideas are nourished by the excitement that allows them to work in a productive manner. They show energy to manage conflicts and to achieve results in their research group, and aggressiveness is not always "affectionate" in removing obstacles.

[...] Doing research in a group is a very positive thing because you aim to get a result and conflicts arise only occasionally...sometimes some conflicts may happen and competition prevails [...] In such groups the dynamics are very complex...the behaviour is similar to that in animal ethology...there are "territories" inside an experiment, so it may happen that you invade someone else's territory. You measure your strength or weakness... you point at your rival... you may use strong words...this is ordinary work dynamics [...]. However, we are not so good at group working as the others are abroad (out of Italy)... So it's typical to conquer your territory by yourself in small groups and when later on you take over a responsibility you never feel inadequate because it is your own conquest...anyway you are alone (Senior male researcher).

This category of employee shows delight in planning scientific work and in building new research paths, even if career progression is very slow. They are proud to belong to the international research world, and they trust their research projects.

However, in some cases motivation fades:

[...] you see that your strong growth has a local impact because you create a group in which you see young colleagues growing with you and you think that it $s$ a virtuous cycle... you are satisfied in doing a job that is your passion... if you don't have all this it is difficult to go on because society considers your work worthless and the institute doesn't defend what you created; the young researchers you trained are forced to go away, so what's the point of going on? I made a career...that's fine but...my motivations can start again if there are changes... (Senior male researcher).

\section{Morphological level}

Female and male researchers. There are several morphological differences, ranging from extremely ordered offices to disordered and neglected ones.

Regarding the positions and postures, the group of both genders is not worried about what happens outside the institute. In terms of mobility, which is the function of personal flexibility, and the ability to change direction and invent 
new paths and solutions to problems, it is not easy to change "position" or "direction", even among female colleagues, because the pride of belonging to the institute prevails.

Women help to make the morphological level alive, taking care of their workplaces (female researchers' offices are clean, well-kept and personalised), but their personal flexibility is hidden and suffocated by INFN immobility. They are strong, determined women able to make things happen, although this strength is not always channelled into institute mechanisms, as the funding of the experiments or the request of new positions are mostly controlled by men.

The female researchers are very dynamic and proactive inside the institute life, but they find it hard to slow down and recover their energy and their enthusiasm. From the interviews, it appears that men are also unable to slow down, but because of a lack of awareness their anxiety is less evident.

\section{Physiological level}

Female and male researchers. Both groups have thoracic breathing, as they cannot slow down and can quickly assimilate novelties as they are used to facing dynamic research needs (which is why they do not like bureaucratic requests). For male researchers, this "breathlessness" translates into greater attention to and concentration on achieving their goals; on the contrary, for female researchers it does not translates into constructive action, but only increases their concern.

It should be underlined how business trips provide moments of social gatherings. The female researchers talked about vigorous and strong exchanges that made relationships enjoyable and lasting, which is why it is necessary to value the moments spent together. Regarding the job reality, they feel certain protection in their work environment, but at the same time, they do not feel that the institute is sensitive to their needs as mothers and women. It is difficult to talk about the function of sounds, since women have lost their female voice, as often they have to adopt a tone of voice which is not their own.

\subsection{Administrative Area}

It is interesting to note that women prevail in this area. Technicians and administrative workers contribute greatly to the life of the institute. Most of the administrative employees have been working for many years at the institute (around 20) and can be considered as part of the historical memory of the organization since they have worked with several structure heads. The administrative area can be seen as the interface between the internal and external world, between the internal dynamics and the requests of the external world of bureaucracy. Most of the interviewees arrived at INFN after several, sometimes troubled, jobs or personal experiences. At first, this new workplace appeared to be happy place, but time, events, requests and the workload contributed to undermining and modifying this perception. Career advancement does not depend on merit, but on the length of service. 
Within this second group, we can observe hidden discrimination. Even if the career levels are the same, with a high school diploma, the technical staff is classified at a higher level (VI) than the administrative (level VII), so they can reach the highest career level (IV) without any graduate qualification, which is required by the administrative staff. Historically, in line with work contracts, the administrative category, populated mainly by women, has been considered ancillary to that of research. This last consideration is not true anymore, but discrimination still persists. The different distribution between men and women at highest levels translates into a gender pay gap (on average an administrative officer earns approximately 1300 euros less than a technician per year). This mechanism is evidence that vertical segregation exists, mostly affecting women's career progression. Moreover, the overrepresentation of women in the administrative area also confirms the existence of horizontal segregation.

\section{Cognitive-Symbolic level}

Female and male. The workload is too heavy for the number of workers and the new informatics procedures do not help in speeding up the work. There is a prevailing sense of tiredness and only their sense of duty and feeling of belonging make the overall system efficient:

[...] From the perspective of work, it got worse... [...] Now it is too much...there are three of us... but the work has increased a lot. I myself do the work of three persons. Everything is bureaucracy and things have become more complicated (Female administrative).

Moreover, the relationship with researchers is not always easy, because they perceive administrative tasks as an obstacle to their research work. The symbolic level shows a split, as the administration employees consider that the institute is innovative, dynamic and modern from the research area side, but on the other hand, the administrative area is slow or unprepared for the continuous public administration changes. Employees often feel they have to face new requests without proper training or sufficient time to adapt. As a consequence, both temporary and permanent staff no longer have dreams, a situation which compromises project functions and the use of resources.

\section{Emotive level}

Female and male. Personal pride and the chance to work in an excellent research center foster their serenity and their curiosity for the work. Peaceful relationships with all their colleagues and with the structure head encourage the ability to keep in contact, which makes vertical communication easier. It should be noted that the excessive workload, which turns excitement into anxiety, often undermines staff's affectionate aggressiveness and serenity.

\section{Morphological level}

Female and male. The function of movements, where it is possible to analyse the speed or the slowness, is damaged, especially the latest, due to continuous requests.

Physiological level

Female and male. A positive basic tension strengthens concentration on per- 
forming tasks, but this often becomes anxiety when the flow of communication towards the world outside to the institute becomes static. Breath is like that of athletes; the metabolism slows down and new events can generate paralysis.

\subsection{Technical Area}

Compared to administrative one, in this area, only men are found. The interviews show the presence of two groups: electronic lab technicians and workshop technicians.

The following interview quotes refer mainly to the electronic lab technicians, who form a cohesive group, and amongst whom collaboration, respect and attention to colleagues' needs are found. Furthermore, the arrival of the latest supervisor has made communication more effective as he did not split the work into several units:

[...] In this lab we talk a lot and listen to each other a lot... and our work in team is what distinguishes us from the exterior world... and collaboration is important in this kind of work (Electronic lab technician).

In this group, passion for their job prevails, which encourages the technicians to keep up-to-date on the latest technologies.

Nevertheless, for all of them family comes first (most of them have a wife or a partner who works), which is why they turn business trips down.

[...] I can't leave my children or ask my wife not to work because I have to go on business trips. Family comes first... (Electronic lab technician).

\section{Cognitive-symbolic level}

The function of capability to plan as well as the functions of symbolism and rationality, are damaged. These three functions are not developed because the group feels the institute is distant from its own needs. The perception is that only the requests of the research groups are fulfilled by the institute. The transmission of knowledge and the use of resources are well structured because the internal management and the balance between the group make their work smooth and stimulating.

\section{Emotive level}

Positive emotions circulate inside the electronic lab, where there is serenity, curiosity and pride to belong to it. They build up a kind of bubble where to work quietly.

\section{Morphological level}

This is the most difficult level because there is the chance of mobility, but they accept to work in different laboratories only if they are in the Naples division. Going abroad for business trips is always a problem for them. The world outside the electronic lab is described as a place of confusion and struggles. However, the morphological level is preserved inside their work environment: the electronic lab is not impersonal and anonymous; it is a pleasant place to have a coffee, and with a comfortable meeting room. The strength level is shown to be resistant as the group is internally determined against the external world.

Physiological level 
This is the smoothest level because there is positive tension, smooth communication, friendly relations with colleagues, a high perceptive ability and a fast metabolism of new things. The electronic lab technicians respect and celebrate moments of aggregation among them during working time. However, everything is different towards the external world.

Regarding the mechanical workshop technicians, everyone is a singularity outside a well-defined working group. The area of the mechanical workshop has no specific identity because the technicians are often on business trips, where they also have different tasks. This is the reason why it is difficult to summarize the group. It can be defined as a "fluid" group that follows the institute logic without being a true group. They demonstrate good dedication to work which gives them certainties; for example:

[...] It's a government job (Mechanical workshop technician).

As well as opportunities to experience different work realities: For instance, they have taken part in experiments in Tibet, the USA and Switzerland, although there have been few career changes:

[...] In twenty years, I had only one advancement...everybody had...so not for my merits. There is neither a career to develop, nor economic pay rises (Mechanical workshop technician).

According to them, only researchers can build a career:

[...] only researchers are important here; they benefit of the best perspectives of the institute (Mechanical workshop technician).

\section{Discussion}

The main research aim of this work has been to capture information about the working conditions inside the INFN Naples division and at the same time to establish the existence of hidden gender discriminatory phenomena. The results of our analysis are representative of the division, but consequently, they are not exhaustive with respect to the physics research world. The sample used was representative of INFN reality, of the characteristics of the workers and of the organization, as identified in previous analysis made as part of the Magellano project. Further improvements to the research could be made by means of comparison and integration with other physics institutes and other STEM (science, technology, engineering and mathematics) disciplines.

From the functional analysis, it results that the emotional level is more damaged in female researchers and technologists than in male ones, and this alteration influences their behaviour in the work environment; for example, when they have to shout to be heard or when they have to struggle to regain their working space, when, for instance, they return from maternity leave. Their perception of time management appears to be completely different from that of men; women are constantly left "short of breath" in an attempt on one hand to satisfy all their job commitments, and on the other those from family and society. They, therefore, struggle to find a work-life balance. 
For the administrative workers (composed mostly of women), the cognitive-symbolic level appears to be more distorted than others because of the excessive workload that does not provide the workers with the serenity to perform their everyday tasks. This creates a break between the cognitive and emotional levels, because on one hand, they feel part of a mission, but on the other the sentiment of personal satisfaction is absent. Most of the workers in the administrative area have low expectations (in terms or wages and career progression) due to negative previous working experiences (for example, related to working sector, occupation, uncertainty or working conditions). Despite that, both horizontal and vertical segregation exist in the area. In fact, to access the same top career level a degree is required only for administrative staff; technicians need just a diploma. It should be noted that this can be considered as an indirect discrimination mechanism, due to the national workers' contract, which applies mostly to women.

In the case of the technicians, the analysis reveals their weak sense of belonging to the institute, which encourages the creation of subgroups with a new balance and dynamics. It is interesting to note that the electronic lab group is the only one that has achieved an equilibrium, with a strong passion both for their jobs and their private lives: they have created a "proper" work dimension, different from the "conventional" one.

A general feeling of dissatisfaction regarding career progression arises from all the employee areas, both for women and men. Moreover, technicians feel they are underestimated compared to researchers and technologists. For the latter, the passion for their work balance is in some way the source of the frustration regarding the lack of career opportunities. In addition to the career problems, administrative staffs feel that their work is insufficiently considered, appearing as a useless burden for research.

All individuals can become trapped in schemes and organizational models, both temporal and relational, and their lack of awareness does not allow them to free themselves of these schemes. In the same way, the institution "protects" itself against changes by keeping the same working models. The same models are handed down over time, as is evident from the link between the cognitive-level of the individuals and that of the institution.

The time over which these schemes evolve and change is different between individuals and organizations. Individuals can experience awareness and empowerment faster than institutes, due to the greater complexity of dynamics that are found in the latter. Individuals and institutions change and evolve at different speeds and in different manners. This is the reason why individuals often feel trapped inside such models and schemes. From our interviews, it emerges that wellbeing is based on a "bien-être" status of all the functions, of all levels. This approach promotes creativity and productivity so that the wellbeing of the employees connects to that of the work organization. The adoption of a gender perspective of work organizations can provide the opportunity to develop organiza- 
tional models that are more compatible with different identities and new capabilities (Naussbaum \& Sen, 1993; Nussbaum, 2000). In the stories we were told, the gender factor acts to weaken the emotional level of women, who feel pushed to wear the clothes of "another one", which weakens their identity level, linking it to the masculine, and unable to move towards the feminine. However, in these stereotypes and models it is not only women, but also men, who are trapped.

Nevertheless, as (Kaës, 1988) underlines, "institutions have to create new common areas, where to build new connections, common representations in which everybody can recognize himself (herself)." Kaës also warns us about the necessity to react to a double dimension: the identity that you feel and the gender identity that the institution, and society, passes on. Such a requirement to go beyond this double dimension (the gender trap) emerged from our narrative interviews.

\section{Conclusion}

The functional analysis, with its measurement methodology (Di Nuovo \& Rispoli, 2011), gave us a reading key on the individual (employees) and the work organization (the INFN Naples division) dynamics. The analysis revealed the existence of hidden mechanisms that sustain gender discrimination, mainly in the research area (i.e. researchers and technologists), where strong identification between employees and their work exists (more than in the other two areas).

For male researchers, the time never becomes an issue, although they seem to be under pressure from their careers. They are able to devote their time to their career without feeling split in half or guilty about the time spent at work disregarding their family duties, or the time spent at home disregarding their work duties. For women, it can be said that such a dichotomous feeling is a source of malaise. Of course, women, like men, suffer from a lack of opportunities in their career progression. However, they have to exert additional efforts simply to indicate that they are equally productive as men. This process triggers additional stress for women, which they carry over into everyday life. Men show less awareness of any anxiety that generally refers to their career, different to women, whose anxiety fundamentally refers to the duality of their roles. For woman researchers in particular, but also for men, the passion and attachment to physics and to their research work are strong enough feelings to create a bias in the perception of reality: The research world is like a fairy tale. However, this world is equivalent to other working environments, where the relationships between individuals and power management mechanisms affect their lives, jobs, and career progression. The ideal world disappears at some point.

The interviews also confirmed the existence of gender discrimination mechanisms such as the implementation of social roles, work organizational models, and productivity indicators, which all refer to rigid gender stereotypes, and are an expression of how society is characterized. This allows us to argue that female workers at the INFN Naples division are discriminated, because their 
quality of life is worse compared to that of their male colleagues, even if there is a lack of awareness of this. For this reason, we believe that this wellbeing gap can be considered as a new dimension of the economic gender discrimination phenomenon.

(Garavaso \& Vassallo, 2007) suggest that in order to make a change within an area of study "to add some representatives of the excluded and mix everything up" is not enough. For a true change, you need to implement a thorough re-thinking of this discipline, wandering whether the methods used so far are accessible to everyone and usable and that if they are not. Then you need to re-think the themes of the research, considering the possibility that problems and questions seen as central and unavoidable in the past, are put aside, substituted and modified". Following this idea, we need to change the paradigm and put the "person", with all her diversities and potentialities, at the centre of the transformation process of organizational models. Each "person" can be productive in a different manner with her various capacities and aspirations: The organizational working model must adapt to the "person", and not vice versa (Comoletti \& D’Isanto, 2019).

Our paper highlights two key points for further research, which are both connected to new work organization models, to the diversity management concept, to the gender dimension of the work: the role and the importance of each person to be put in the center of transformation processes and necessity to investigate better the connection between woman wellbeing and work organizations, and power relationships.

An analysis of working organizations that includes a gender wellbeing measurement underlines the existence of a clear mismatch between the employer understandings of well-being and the employee perceptions, true not only for women. A more inclusive analysis could be very useful in the future, especially in crisis events (for example, financial shocks, pandemics, and natural phenomena), during which there is evidence that women are the most penalized in terms of inequalities. Being work organizational models inserted into the model of society, a wider transforming perspective can be achieved only through the promotion of human and social capital. We believe that the search for a gender-equal society is important, not only in the context of purely gender issues but also as a resource for tackling all political and social sectors from a gender perspective (SAAGE, 2019).

\section{Conflicts of Interest}

The authors declare no conflicts of interest regarding the publication of this paper.

\section{References}

Aaltio, I., \& Mills, A. J. (2003). Gender, Identity and the Culture of Organizations. Routledge Press. https://doi.org/10.4324/9780203166758

Acker, J. (1990). Hierarchies, Jobs, Bodies: A Theory of Gendered Organizations. Gender and Society, 4, 139-158. https://doi.org/10.1177/089124390004002002 
Acker, J. (1992). From Sex Roles to Gendered Institutions. Contemporary Sociology, 21, 565-569. https://doi.org/10.2307/2075528

Anker, R. (1997). Theories of Occupational Segregation by Sex: An Overview. International Labour Review, 136, 315-339.

Batz, C., \& Tay, L. (2018). Gender Differences in Subjective Well-Being. In E. Diener, S. Oishi, \& L. Tay (Eds.), Handbook of Well-Being (pp. 1-15). DEF Publishers.

Becker, G. (1957). The Economics of Discrimination. University of Chicago Press.

Becker, G. (1975). Human Capital: A Theoretical and Empirical Analysis, with Special Reference to Education. University of Chicago Press.

Becker, G. (1985). The Allocation of Effort, Specific Human Capital, and Differences between Men and Women in Earnings and Occupations. Journal of Labor Economics, 3, 33-58. https://doi.org/10.1086/298075

Bergman, B. (1974). Occupational Segregation, Wages and Profits When Employers Discriminate by Race and Sex. Eastern Economic Journal, 2, 103-110.

Bettio, F. (2008). Occupational Segregation and Gender Wage Disparities in Developed Economies: Should We Still Worry. In F. Bettio, \& A. Veraschagina (Eds.), Frontiers in the Economics of Gender (pp. 167-192). Taylor and Francis, Routledge. https://doi.org/10.4324/9780203927694.ch9

Blinder, A. S. (1973). Wage Discrimination: Reduced Form and Structural Estimates. Journal of Human Resources, 8, 436-55. https://doi.org/10.2307/144855

Bruni, A., Gherardi, S., \& Poggio, B. (2004). Doing Gender, Doing Entrepreneurship: An Ethnographic Account of Intertwined Practices. Gender, Work and Organizations, 11, 406-429. https://doi.org/10.1111/j.1468-0432.2004.00240.x

COM 392 Final Report (2012). A Reinforced European Research Area Partnership for Excellence and Growth Communication from the Commission to the European Parliament. The Council and the European Economic and Social Committee and the Committee of the Regions.

Comoletti, C., \& D’Isanto F. (2019). Gender Discrimination and Self-Selective Abortion. Description of the Phenomenon and Intervention Policies in Support to the Human Development. G. Giappichelli Press.

Connerley, M. L., \& Wu, J. (2019). Handbook on Well-Being of Working Women. Springer.

D’Isanto, F. (2013). Gender Segregation and Wage Differentials in the Italian Labor Market. The Case of Non-Profit Organizations. G. Giappichelli Press.

Denzin, N. K. (1989). Interpretive Biography. Sage Publications Inc. https://doi.org/10.4135/9781412984584

Di Nuovo, S., \& Rispoli, L. (2011). Functional Analysis of the Stress. From the Clinic to Applied Psychology. Franco Angeli Press.

Garavaso, P., \& Vassallo, N. (2007). The Philosophy of Women. Laterza.

Gherardi, S., \& Poggio, B. (2007). Gendertelling in Organizations. Narratives from Male-Dominated Environments. Copenhagen Business School Press.

Global Research Council (2016). Equality and Status for Women in Research. Careers Research and Advisory Centre (CRAC) Limited.

Greig, F., Hausmann, R., Tyson, L.D., R., \& Zahidi, S., (2018) The Global Gender Gap Report 2018. World Economic Forum.

Harding, S. (1987). Feminism and Methodology: Social Science Issues. Indiana University Press.

Huyer, S. (2015). Is the Gender Gap Narrowing in Science and Engineering? UNESCO Science Report: Towards 2030 (pp. 84-103). UNESCO Publishing. 
https://doi.org/10.18356/9789210059053c009

Instituto Nazionale di Fisica Nucleare (INFN) (2018) Map of INFN Facilities. https://home.infn.it/en/structure/map-of-infn-facilities

Kaës, R. (1988). L'institution et les institutions-Études psychanalytiques. Dunod Press.

Lennon, M. C. (1994). Women, Work, and Well-Being: The Importance of Work Conditions. Journal of Health and Social Behavior, 35, 235-247. https://doi.org/10.2307/2137278

Lewin, K. (1947). Frontiers in Group Dynamics: Concept, Method and Reality in Social Science; Social Equilibria and Social Change. Human Relations, 1, 5-40. https://doi.org/10.1177/001872674700100103

Maes, K., Gvozdanovic, J., Buitendijk, S., Hallberg, I. R., \& Mantilleri, B. (2012). Women, Research and Universities. Excellence without Gender Bias. League of European Research Universities.

Meisenberg, G., \& Woodley, M. A. (2015). Gender Differences in Subjective Well-Being and Their Relationships with Gender Equality. Journal of Happiness Studies, 16, 1539-1555. https://doi.org/10.1007/s10902-014-9577-5

Naussbaum, M. C., \& Sen, A. (1993). The Quality of Life. Clarendon Press. https://doi.org/10.1093/0198287976.001.0001

Nielsen, M. W., Bloch, C. W., \& Schiebinger, L. (2018). Making Gender Diversity Work for Scientific Discovery and Innovation. Nature Human Behaviour, 2, 726-734. https://doi.org/10.1038/s41562-018-0433-1

Nussbaum, M. C. (2000). Women and Human Development: The Capabilities Approach. Cambridge University Press. https://doi.org/10.1017/CBO9780511841286

Oaxaca, R., \& Ransom, M. (1994). On the Discrimination and the Decomposition of Wage Differentials. Journal of Econometrics, 61, 5-21. https://doi.org/10.1016/0304-4076(94)90074-4

Poggio, B. (2006). Outline of a Theory of Gender Practices. Gender, Work and Organizations, 13, 225-233. https://doi.org/10.1111/j.1468-0432.2006.00305.x

Powell, A., Bagilhole, B., \& Dainty, A. (2009). How Women Engineers Do and Undo Gender: Consequences for Gender Equality. Gender, Work and Organizations, 16, 411-428. https://doi.org/10.1111/j.1468-0432.2008.00406.x

Ravenswood, K., Harris, C., \& Wrapson, W. (2017). Gender \& Wellbeing at Work. New Zealand Journal of Employment Relations, 42, 1-6.

Rispoli, L. (2008). The Basic Experience and the Development of the Self. Development from the Point of View of Functional Psychotherapy. Peter Lang AG International Academic Publishers

Rolin, K., \& Vainio J. (2011). Gender in Academia in Finland: Tensions between Policies and Gendering Processes in Physics Departments. Science \& Technology Studies, 24, 26-46. https://doi.org/10.23987/sts.55268

SAAGE (2019). New Vision for Gender Equality. Niall Crowley \& Silvia Sansonetti.

She Figures 2018 Report (2018) European Commission. Research and Innovation-Report. Publications Office of the European Union.

Williams, C. L., Muller, C., \& Kilanski, K. (2012). Gendered Organizations in the New Economy. Gender \& Society, 26, 549-573. https://doi.org/10.1177/0891243212445466

Wood, W., \& Ridgeway C. L. (2010) Gender: An Interdisciplinary Perspective. Social Psychology Quarterly, 73, 334-339. https://www.jstor.org/stable/27896249 https://doi.org/10.1177/0190272510389005 